\title{
Assessment of midpalatal suture ossification using cone-beam computed tomography
}

Sina Haghanifar ${ }^{1}$, Sadaf Mahmoudi ${ }^{2}$, Ramin Foroughi ${ }^{3}$, Arash Poorsattar Bejeh Mir $^{4}$, Abas Mesgarani ${ }^{5}$, Ali Bijani $^{6}$

${ }^{1}$ DDS, MS, Associate Professor, Department of Oral and Maxillofacial Radiology, Faculty of Dentistry, Babol University of Medical Sciences, Babol, Iran

${ }^{2}$ DDS, Dentist, Dental Faculty, Babol University of Medical Sciences, Babol, Iran

${ }^{3}$ DDS, MS, Assistant Professor, Department of Oral and Maxillofacial Surgery, Faculty of Dentistry, Babol University of Medical Sciences, Babol, Iran

${ }^{4}$ DDS, Researcher, Dental Materials Research Center, Dentistry School, Babol University of Medical Sciences, Babol, Iran

${ }^{5}$ DDS, MS, Assistant Professor, Department of Endodontics, Faculty of Dentistry, Mazandaran University of Medical Sciences, Sari, Iran

${ }^{6}$ M.D, General Practitioner, Non Communicable Pediatric Diseases Research Center, Babol University of Medical Sciences, Babol, Iran

\section{Type of article: Original}

\begin{abstract}
Background and Objective: The degree of ossification of the midpalatal suture is an important factor in the selection of treatment procedure, especially in young individuals. Considering the discrepancies in the results of studies on the exact time of the closure of this suture, the present study was undertaken to evaluate ossification and morphology of the suture with the use of CBCT.

Methods: In the present cross-sectional study, the CBCT images of the maxilla in 144 Iranian subjects (72 males, 72 females) with an age range of 10 to 70 years, referring to a private radiology center in Sari, Iran, were evaluated. The CBCT images were evaluated in the axial cross-sectional slice at $1 \mathrm{~mm}$ intervals to determine morphology and the maturation stage of the suture and its degree of ossification. The six developmental stages that were observed were as follows: stage A, a direct line without disturbances; stage B, a scalloped appearance in the suture; stage C, two parallel lines with a scalloped appearance that were connected at some points; stage $\mathrm{CD}$, the anterior portion was similar to stage $\mathrm{C}$, and the posterior region was similar to stage $\mathrm{D}$; stage $\mathrm{D}$, ossification only in the palatine bone; stage E, complete ossification of the suture. The degree of ossification of the suture was calculated with the use of the ratio of the length of the ossified segment to the entire length of the suture. Data were analyzed with Spearman's correlation test, Chi-squared test, t-test, ANOVA, Mann-Whitney U, and Kruskal-Wallis test. Intraobserver agreement was calculated with the use of weighted kappa coefficient. Data were analyzed with SPSS 17. Results: There was a strong correlation between the age groups and the developmental stages of the midpalatal suture in both genders $(\mathrm{r}=0.681, \mathrm{p}<0.001)$. The ossification process occurred in the posterior to anterior direction in $98 \%$ of the cases. There was a significant relationship between aging and the degree of ossification $(\mathrm{p}<0.001)$; however, the difference was not significant between the two genders $(\mathrm{p}=0.193)$.

Conclusion: Although the rate of suture closure increased with aging, age was not a reliable factor alone to determine the developmental stage of the suture. Use of CBCT is necessary in all the patients to determine the degree of ossification and morphology of the midpalatal suture.
\end{abstract}

Keywords: Cone-beam computed tomography, Maxillary expansion, Ossification, Suture

\section{Corresponding author:}

Dr. Sadaf Mahmoudi, Dental Faculty, Babol University of Medical Sciences, Babol, Iran.

Tel: +98.9358232331,+98.1132291408, Email: mahmoudi.sadaf@yahoo.com

Received: July 12, 2016, Accepted: September 27, 2016, Published: March 2017

iThenticate screening: August 31, 2016, English editing: December 17, 2016, Quality control: February 12, 2017

(C) 2017 The Authors. This is an open access article under the terms of the Creative Commons Attribution-NonCommercialNoDerivs License, which permits use and distribution in any medium, provided the original work is properly cited, the use is noncommercial and no modifications or adaptations are made. 


\section{Introduction}

Rapid maxillary expansion (RME) is a procedure with a long history and is the most effective orthopedic approach for expanding and increasing the transverse dimension and correcting the transverse discrepancies through increasing the intermolar width, opening the midpalatal suture and separating the two halves of the maxillary bone with the use of forces of large magnitude (1-9). Gradually, the two halves of the maxillary bone interdigiated to some extent and cannot be separated from each other even with force and in-office appliances; the only way to separate the two halves is through surgery or surgically assisted rapid maxillary expansion (SARME) (10). Contrary to other cranial sutures, the midpalatal suture in human beings is the only suture that might not close up in the elderly (11); thus, decision to carry out SARME or RME should not be made only based on the chronological age $(10,12,13)$. Although SARME is possible at any age, it is a more aggressive approach and imposes extra costs and gives rise to problems for both the patient and the orthodontist (3). Different studies on the morphology and degree of fusion of the suture and its initiation time in different individuals have yielded wide variations at the time of initiation and progression of the closure of the suture $(3,14-16)$; some cases of completely open sutures have been reported in subjects over 18 years of age $(10,14$, $17,18)$. Based on a study by Melsen, the morphology of the suture changes at each stage of development (19). Changes are observed in the biologic behavior, morphology, and an increase in the density with aging and skeletal maturation (20). In the past, maxillary occlusal radiographs were used for the evaluation of inter-maxillary suture; on such radiographs, it is difficult to carry out an antero-posterior evaluation of the suture because the image is a $2 \mathrm{D}$ representation of a 3D structure, and, due to the superimposition of the nasal structures and the vomer bone on the midpalatal area, misinterpretation of the radiography and discrepancy with morphologic findings are possible $(14,21)$. $\mathrm{CT}$ and $\mathrm{CBCT}$ techniques are alternative techniques that can provide $3 \mathrm{D}$ and high-resolution images of craniofacial structures $(5,16,20)$. Another characteristic of these techniques is their high dimensional accuracy and their reliability for the evaluation of inter-maxillary suture, noninvasive nature, saving time, easy access, and lack of anatomic superimposition $(5,20,22)$. Given the discrepancies between the results of studies on the time of initiation and progression of the closure of the suture $(18,23,24)$, the present study was undertaken to evaluate the morphology and the degree of closure of the inter-maxillary suture in different age groups in both genders with the use of CBCT technique.

\section{Material and Methods}

\subsection{Design and setting}

A total of 144 CBCT images of the maxilla of Iranian subjects ( 72 males and 72 females) were evaluated in the present descriptive study. The subjects were 10-70 years of age, with a mean age of 39.62 17.31 years and had been referred to a private maxillofacial radiology center in 2014-2016 in Sari, Iran, for diagnostic reasons. The subjects were grouped in 10-year groups.

\subsection{Sampling and eligibility criteria}

The sample size was calculated at 138 by assuming $\sigma=15 \%, \mathrm{CI}=95 \%$, and an accuracy rate of $2.5 \%$, but 144 subjects were included for proper age and sex distribution. The samples were selected randomly. Subjects with a history of any systemic disease related to bone metabolism or a history of taking drugs related to such problems and those with a history of orthodontic treatment were excluded from the study.

\subsection{Measurement tool}

All the CBCT images were taken with a Cranex 3D CBCT unit (Cranex 3D Soredex, Helsinki, Finland) with a flat panel detector using the following exposure settings: $\mathrm{kVp}=89, \mathrm{~mA}=6$, voxel size $=0.2, \mathrm{FOV}=6 \times 8 \mathrm{~cm}$, and highresolution option. The images were analyzed with "OnDemand3 $\mathrm{D}^{\mathrm{TM}}$ Dental" software programs to evaluate maturational stage of the midpalatal suture and the degree of suture closure using the following steps.

\subsection{Assessment of midpalatal suture morphology}

First, the horizontal line of the image analysis software was used on the sagittal plane to position the palate horizontally in order to evaluate the morphology and maturation stages of the suture. The head was moved downward or upward to make the antero-posterior axis of the palate parallel with the horizon line of the software program (Figure 1). Then, the morphology and developmental stage of the midpalatal suture was determined on the axial plane in the superoinferior dimension, i.e., from the level of the nose to the oral level of the palate. In subjects with a curved palate, i.e., in subjects in whom the anterior and posterior segments of the palate are not seen in one axial slice, the palate was evaluated separately in two anterior and posterior central cross-sectional axial slices along the midpalatal suture (Figure 2). The morphology and the maturational stage of the midpalatal suture were determined based on a classification introduced by Angelieri et al. (23) by an experienced oral and maxillofacial radiologist. 


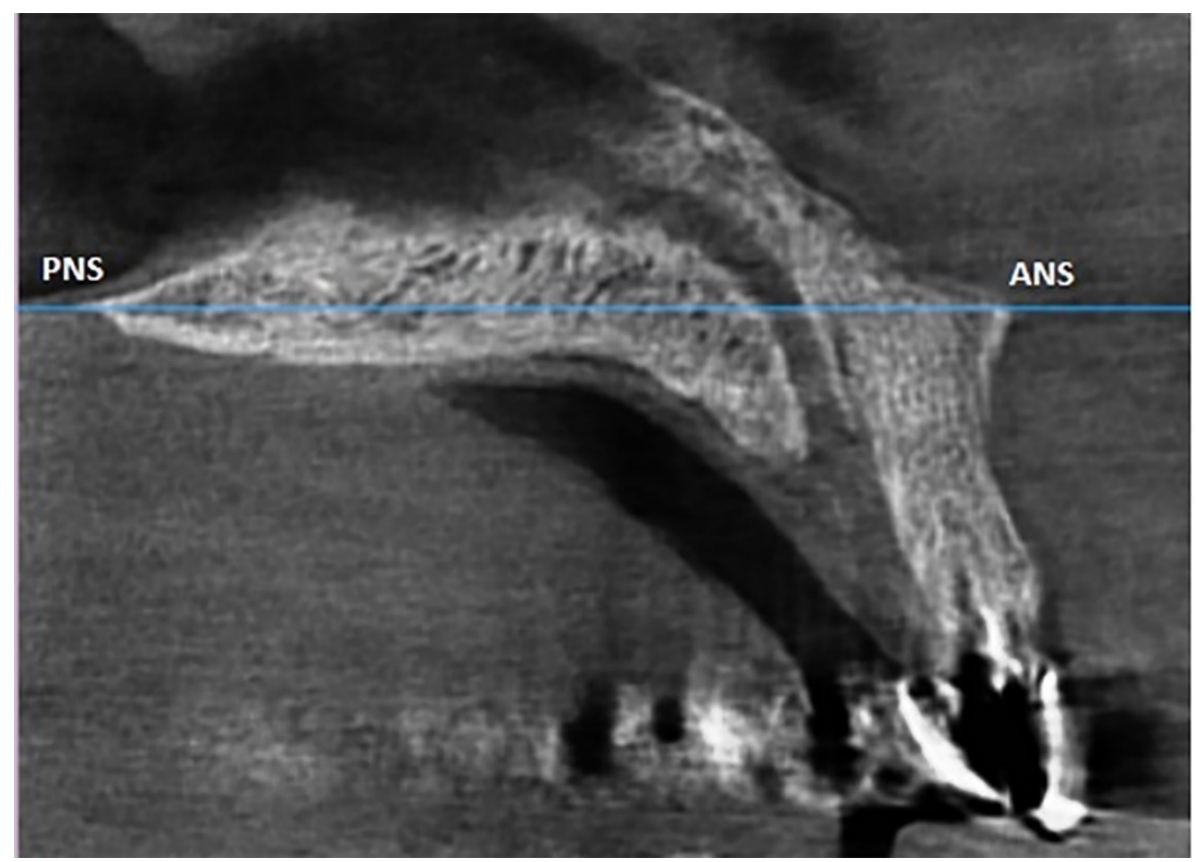

Figure 1. Line from ANS to PNS in order to position the palate horizontally

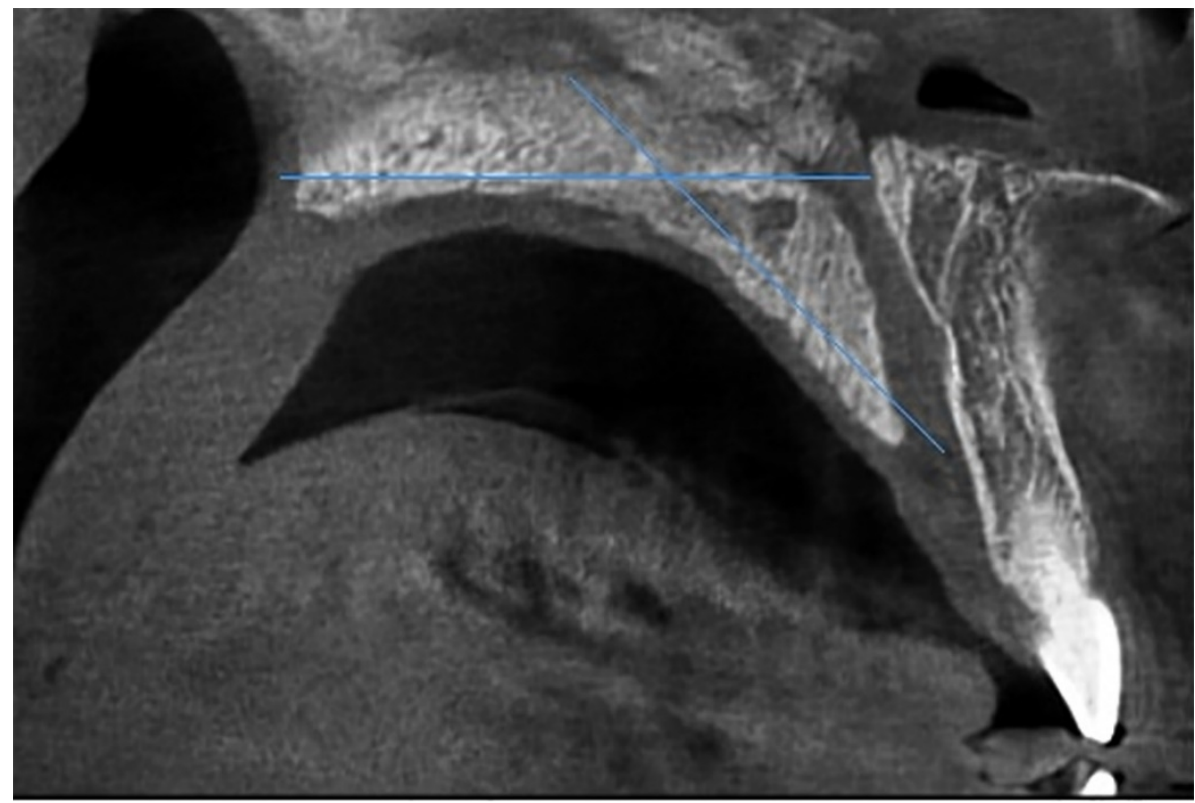

Figure 2. For curved palate subjects, two central cross-sectional axial slices in posterior and anterior regions of the palate were considered

\subsection{Calculation of the percentage of ossification of the midpalatal suture}

To acquire the obliteration index (24), axial cross-sections were used. A line was drawn from ANS to PNS; then, first, the overall length of the suture and then the length of the ossified segment was measured, and the obliteration index was calculated using the following formula:

$\mathrm{OI}=($ length of midpalatal suture ossification $) /($ total length of midpalatal suture $) \times 100$

\subsection{Statistical analyses}

In order to acquire the intra-observer agreement coefficient, two weeks after the initial analysis, $10 \%$ of the CBCT images were selected randomly and the suture developmental stage, its overall length, and the degree of suture fusion were evaluated and classified again using the method described above. The agreement coefficients for quantitative 
values, i.e., the total length of the suture and the degree of ossification, were calculated at $90 \%$ and $100 \%$, respectively, and at $85 \%$ for qualitative values with the use of weighted kappa coefficient. Data were analyzed with SPSS version 17 (SPSS Inc., Chicago, Illinois, USA). Spearman's correlation test was used to evaluate the maturational stage in different age groups; Chi-squared test was used to compare the two genders. In addition, Chi-squared test was used to analyze groups and the two genders. A Kalmogorov-Smiranov test was used to evaluate the normal distribution of data in order to evaluate the quantitative variables in different groups. Variables that were distributed normally were analyzed with t-test and ANOVA and those that were not distributed normally were analyzed with Mann-Whitey U and Kruskal-Wallis tests. Statistical significance was set at $\mathrm{p}<0.05$.

\section{Results}

In the present study, the developmental stage, the overall length, and the degree and percentage of ossification of the midpalatal suture in 10-year age groups were determined in 72 males and females with mean ages of $39.42 \pm 17.68$ and $39.83 \pm 17.06$ years, respectively. Evaluation of the developmental stage of the suture in different age groups, irrespective of gender, showed a percentage of $53.8 \%$ for stage $\mathrm{A}$ in the 10- to 19-year-old age group (10 females and 11 males), with lower percentages in the other age groups. None of the subjects in the 50- to 59-year-old age group exhibited this developmental stage, and in the $>60$-year age group only one female subject exhibited stage A. The distribution of stage B was almost similar in all the age groups. Stage C rates were $31.2 \%$ in the 20 - to 29 -year age group and $34.3 \%$ in the $30-39$-year age group. In other age groups, this stage had lower rates. In the 10- to 19-year age group, this stage was detected in only one female subject. In addition to the stages mentioned in the study by Angelieri et al. (23), in the present study a new form was observed, in which the anterior segment of the suture (anterior to the nasopalatine foramen) was similar to stage $\mathrm{C}$, and its posterior region was similar to stage $\mathrm{D}$. This new form is, in fact, a stage between stage $\mathrm{C}$ and stage $\mathrm{D}$ and was dubbed stage $\mathrm{CD}$ (Figure 3).

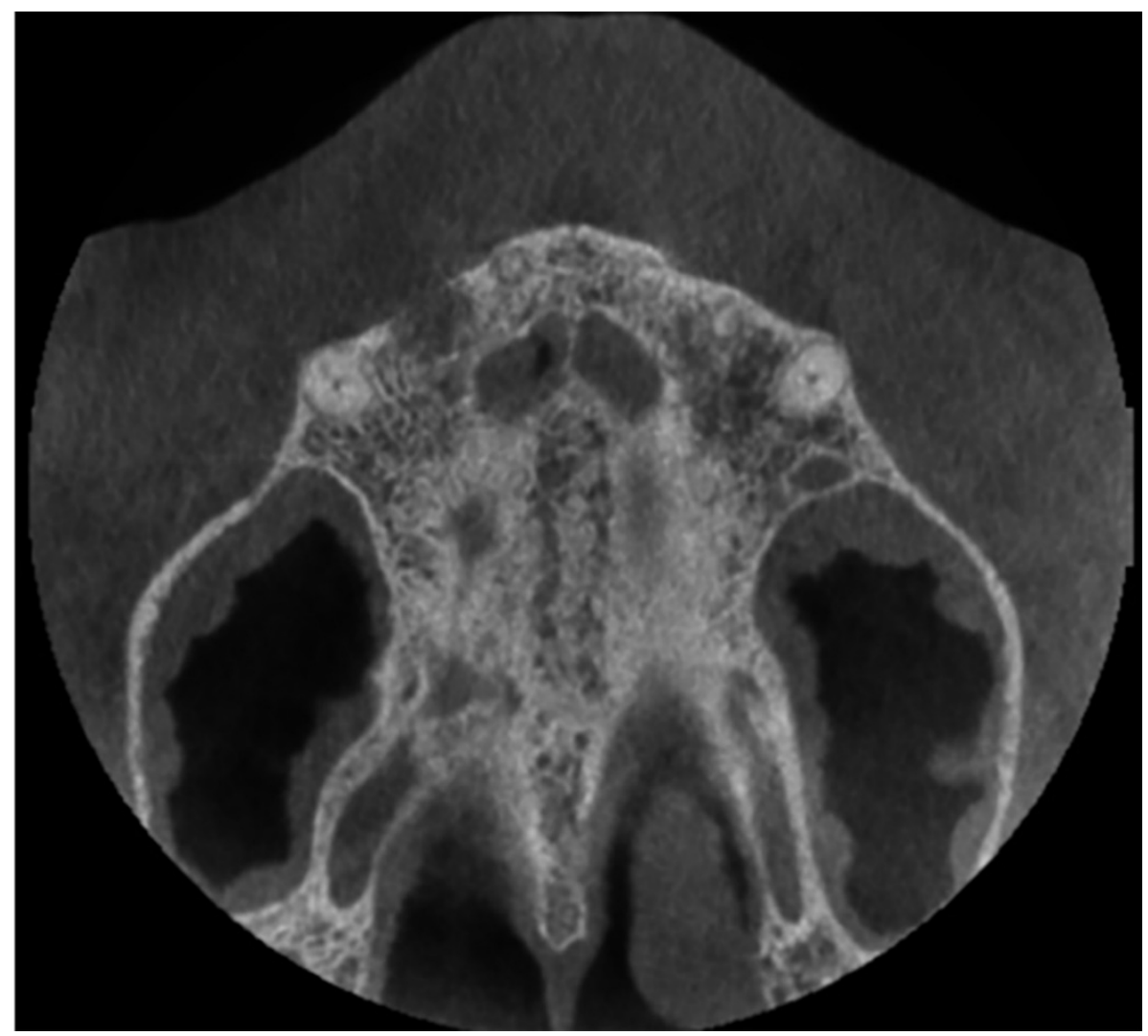

Figure 3. Stage $\mathrm{CD}$ of the maturation stages observed in the midpalatal suture

In the present study, $8.3 \%$ of female subjects and $9.7 \%$ of male subjects were in this stage. This stage was not detected in the 10- to 19-year age group. Stage D was observed only in the subjects in $>40$ years old. Stage $\mathrm{E}$ was detected in none of the two first age groups (10-19 and 20-29) and was mainly detected (47\%) in the $>50$ years old. Spearman's correlation coefficient showed a high rate of correlation between the age groups and the developmental stage of the 
suture. In this context, the developmental stage of the midpalatal suture progressed to stage $\mathrm{E}$ with aging ( $\mathrm{r}=0.681$, $\mathrm{p}<0.001)$, with no significant difference between males and females $(\mathrm{p}=0.777)$. In relation to the point of initiation of ossification, in all the age groups in both genders, ossification began from the posterior region of the transverse palatine suture toward the anterior region. In only one 54-year-old female subject of 144 subjects, ossification occurred in the antero-posterior direction, and in one 49-year-old female subject and one 36-year-old male subject ossification had begun from the middle area. The overall lengths of the suture in female and male subjects were $52.75 \pm 2.97$ and $55.63 \pm 3.40 \mathrm{~mm}$, respectively, with a significant difference between males and females $(\mathrm{p}=0.011)$. The rates of ossification of the mid-palatal suture in female and male subjects were $13.55 \pm 20.6$ and $18.48 \pm 24.34$, respectively $(p=0.193)$. In general the degree of ossification of the suture increased with aging in both genders and the relationship was statistically significant $(\mathrm{p}<0.001)$.

\section{Discussion}

In the present study, the degree of ossification of the midpalatal suture and the relationship between its developmental stage and age and gender were evaluated. The results of the present study in relation to the degree of ossification of the suture in the 10-year age groups showed that ossification increased with aging; however, some cases of completely open sutures were observed in the $>20$-year age groups. The results of the present study are consistent with those of previous studies $(10,11,18,25)$. Nguyen (2008) carried out a study on 20 patients over 70 years of age and reported that the midpalatal suture is the only suture that might not close completely even in the elderly (11). In addition, in a study by Poorsattar et al., some cases of incomplete ossification of the suture were observed at ages $>40$ years (10). In another study with the use of CBCT images, in only $13 \%$ of the adult subjects completely closed sutures were detected (25). In addition, the results of 30 micro-CT analyses in a study by Krobmacher et al. in 28 patients 14 to 17 years of age showed no significant relationship between closure of the suture and age (18). Based on a hypothesis by Cohen, there is no relationship between the termination of growth and closure of the suture, i.e., even if $95 \%$ of the growth of the maxilla ends at 7 years of age, the suture is not necessarily closed (26). Studies have attributed the open suture in adults to a decrease in the functional forces of muscles due to aging and loss of teeth or use of a softer diet due to poor health; thus, the relative course of development of the midpalatal suture depends on the masticatory forces exerted on the maxillary bone during life, and, contrary to other cranial sutures, the mechanical forces such as the forces of mastication affect the ossification process and morphology of the suture $(11,27)$. Therefore, chronological age alone is not suitable to determine the developmental stage of the suture and should be considered in association with the effects of hormonal and genetic factors and mechanical forces on the ossification of the suture (14, 18, 23). In the present study, the effect of gender on the degree of ossification of the suture was not significant; thus, only a significant increase in ossification in females was observed one decade later compared with males, which is contrary to the results reported by Chracanovic and de Fátina Batista, who believed that closure of the suture and skeletal maturation in females occurred earlier than that in males (3, 28). However, in the study by Nguyen (2007), no relationship was found between gender and the closure of the midpalatal suture, which is consistent with the results of the present study (25). In a study by Angelieri et al. (2012) on CBCT images of 140 patients with an age range of 5.6-58.4 years, subjects over 11 year of age exhibited all the developmental stages mentioned above for the midpalatal suture. The authors also reported that the chronological age was an invalid criterion for determining the developmental stage of the midpalatal suture during growth (23). In the present study, too, evaluation of the morphology of the suture in 10-year age groups revealed wide variations in subjects over 20 years of age, with $50 \%$ of the subjects over 20 years of age in stages A, B, and C of the development of the suture; in these stages, completely open sutures are observed. In addition, these results are consistent with those reported by Reveolo et al., who showed that, although there is a significant relationship between completion of growth and initiation of ossification of the midpalatal suture, there are wide variations between the individuals in the ossification process (29). In a study by Fricke-Zech et al., it was reported that morphologic changes in suture are wide in different individuals and are not related to age only (13). In the present study, evaluation of the suture morphology did not reveal any significant differences between males and females, which is consistent with the results of a study by Revelo et al. on 84 subjects ( 39 males and 45 females) with an age range of 8 to 18 years (29). The results of the present study showed the postero-anterior direction of ossification of the suture. Malison et al., too, showed the formation of several osseous bridges in adults in the postero-anterior direction and from the oral side to the nose (19). The results of a study by Knaup et al., too, are consistent with those of the present study (17). Finally, CBCT is an effective technique for the evaluation of the degree of ossification and the developmental stage of the midpalatal suture irrespective of age due to the multiple views it provides and its low radiation dose, facilitating decisions about the use of rapid maxillary expansion, or the more aggressive surgically assisted rapid maxillary expansion, especially in young patients. 


\section{Conclusions}

The results of the present study showed a wide variation in the initiation time and the degree of ossification and morphology of the midpalatal suture in different age groups. Based on the results of the present study, although there was an increase in the closure of the suture with aging, age is not a reliable criterion for determining the open or closed nature of the suture. This finding is important in preparing an appropriate orthodontic treatment plan, irrespective of the patients' age. Therefore, use of 3D imaging techniques such as CBCT is suggested to determine the degree of ossification and morphology of the midpalatal suture in all the patients. It is suggested that a similar study be carried out with a larger sample size to pave the way for future studies.

\section{Acknowledgments:}

The present study was based on a research plan under the code 9339616 in the form of a thesis for a degree in dentistry in Babol Faculty of Dentistry. The study was supported financially by the Deputy Dean of Research of Babol University of Medical Sciences.

\section{Conflict of Interest:}

There is no conflict of interest to be declared.

\section{Authors' contributions:}

All authors contributed to this project and article equally. All authors read and approved the final manuscript.

\section{References:}

1) Lione R, Ballanti F, Franchi L, Baccetti T, Cozza P. Treatment and posttreatment skeletal effects of rapid maxillary expansion studied with low-dose computed tomography in growing subjects. Am J Orthod Dentofacial Orthop. 2008; 134(3): 389-92. doi: 10.1016/j.ajodo.2008.05.011. PMID: 18774085.

2) Baccetti $\mathrm{T}$, Franchi L, Cameron CG, McNamara Jr JA. Treatment timing for rapid maxillary expansion. Angle Orthod. 2001; 71(5): 343-50. doi: 10.1043/0003-3219(2001)071<0343:TTFRME>2.0.CO;2. PMID: 11605867.

3) Chrcanovic BR, Custódio AL. Orthodontic or surgically assisted rapid maxillary expansion. Oral maxillofac surg. 2009; 13(3): 123-37. doi: 10.1007/s10006-009-0161-9. PMID: 19590910.

4) Lione R, Franchi L, Fanucci E, Laganà G, Cozza P. Three-dimensional densitometric analysis of maxillary sutural changes induced by rapid maxillary expansion. Dentomaxillofac Radiol. 2013; 42(2): 71798010. doi: 10.1259/dmfr/71798010. PMID: 22996394, PMCID: PMC3699014.

5) Phatouros A, Goonewardene MS. Morphologic changes of the palate after rapid maxillary expansion: a 3dimensional computed tomography evaluation. Am J Orthod Dentofacial Orthop. 2008; 134(1): 117-24. doi: 10.1016/j.ajodo.2007.05.015. PMID: 18617111.

6) Garrett BJ, Caruso JM, Rungcharassaeng K, Farrage JR, Kim JS, Taylor GD. Skeletal effects to the maxilla after rapid maxillary expansion assessed with cone-beam computed tomography. Am J Orthod Dentofacial Orthop. 2008; 134(1): 8-9. doi: 10.1016/j.ajodo.2008.06.004. PMID: 18617096.

7) Kumar SA, Gurunathan D, Muruganandham SS, Kumar SA. Rapid Maxillary Expansion: A Unique Treatment Modality in Dentistry. J Clin Diagn Res. 2011; 5(4): 906-11.

8) Romanyk DL, Liu SS, Lipsett MG, Toogood RW, Lagravère MO, Major PW, et al. Towards a viscoelastic model for the unfused midpalatal suture: Development and validation using the midsagittal suture in New Zealand white Rabbits. J Biomech. 2013; 46(10): 1618-25. doi: 10.1016/j.jbiomech.2013.04.011. PMID: 23684080 .

9) Larson CE. Midpalatal suture density ratio as a predictor of skeletal response to rapid maxillary expansion. (Doctoral dissertation): University of Minnesota. 2015.

10) Poorsattar Bejeh Mir K, Poorsattar Bejeh Mir A, Bejeh Mir MP, Haghanifar S. A unique functional craniofacial suture that may normally never ossify: A cone-beam computed tomography-based report of two cases. Indian J Dent. 2016; 7(1): 48-50. doi: 10.4103/0975-962X.179375. PMID: 27134455, PMCID: PMC4836098.

11) N'Guyen T, Ayral X, Vacher C. Radiographic and microscopic anatomy of the mid-palatal suture in the elderly. Surg Radiol Anat. 2008; 30(1): 65-8. doi: 10.1007/s00276-007-0281-6. PMID: 18049790.

12) Hahn W, Fricke-Zech S, Fialka-Fricke J, Dullin C, Zapf A, Gruber R, et al. Imaging of the midpalatal suture in a porcine model: flat-panel volume computed tomography compared with multislice computed tomography. Oral Surg Oral Med Oral Pathol Oral Radiol Endod. 2009; 108(3): 443-9. doi: 10.1016/j.tripleo.2009.02.034. PMID: 19464211. 
13) Fricke-Zech S, Gruber RM, Dullin C, Zapf A, Kramer FJ, Kubein-Meesenburg D, et al. Measurement of the midpalatal suture width. Angle Orthod. 2012; 82(1): 145-50. doi: 10.2319/040311-238.1. PMID: 21812573.

14) Wehrbein H, Yildizhan F. The mid-palatal suture in young adults. A radiological - histological investigation. Eur J Orthod. 2001; 23(2): 105-14. doi: 10.1093/ejo/23.2.105. PMID: 11398548.

15) Primožič J, Perinetti G, Richmond S, Ovsenik M. Three-dimensional longitudinal evaluation of palatal vault changes in growing subjects. Angle Orthod. 2012; 82(4): 632-6. doi: 10.2319/070111-426.1. PMID: 22011097.

16) Angelieri F, Franchi L, Cevidanes LH, McNamara Jr JA. Diagnostic performance of skeletal maturity for the assessment of midpalatal suture maturation. Am J Orthod Dentofacial Orthop. 2015; 148(6): 1010-6. doi: 10.1016/j.ajodo.2015.06.016. PMID: 26672707.

17) Knaup B, Yildizhan F, Wehrbein H. Age-related changes in the midpalatal suture. J Orofac Orthop. 2004; 65(6): 467-74. doi: 10.1007/s00056-004-0415-y. PMID: 15570405.

18) Korbmacher H, Schilling A, Püschel K, Amling M, Kahl-Nieke B. Age-dependent Three-dimensional Microcomputed Tomography Analysis of the Human Midpalatal Suture. J Orofac Orthop. 2007; 68(5): 36476. doi: 10.1007/s00056-007-0729-7. PMID: 17882364.

19) Melsen B. Palatal growth studied on human autopsy material: a histologic microradiographic study. Am J Orthod. 1975; 68(1): 42-54. PMID: 1056143.

20) Salgueiro DG, Rodrigues VH, Tieghi Neto V, Menezes CC, Gonçales ES, Ferreira Júnior O. Evaluation of opening pattern and bone neoformation at median palatal suture area in patients submitted to surgically assisted rapid maxillary expansion (SARME) through cone beam computed tomography. J Appl Oral Sci. 2015; 23(4): 397-404. doi: 10.1590/1678-775720140486. PMID: 26398512, PMCID: PMC4560500.

21) Acar YB, Motro M, Erverdi AN. Hounsfield Units: A new indicator showing maxillary resistance in rapid maxillary expansion cases? Angle Orthod. 2014; 85(1): 109-16. doi: 10.2319/111013-823.1. PMID: 24784845.

22) Ribeiro GLU, Locks A, Pereira J, Brunetto M. Analysis of rapid maxillary expansion using Cone-Beam Computed Tomography. Dental Press J Orthod. 2010; 15(6): 107-12. doi: 10.1590/S217694512010000600014.

23) Angelieri F, Cevidanes LH, Franchi L, Gonçalves JR, Benavides E, McNamara Jr JA. Midpalatal suture maturation: Classification method for individual assessment before rapid maxillary expansion. Am J Orthod Dentofacial Orthop. 2013; 144(5): 759-69. doi: 10.1016/j.ajodo.2013.04.022. PMID: 24182592, PMCID: PMC4185298.

24) Thadani M, Shenoy U, Patle B, Kalra A, Goel S, Toshinawal N. Midpalatal Suture Ossification and Skeletal Maturation: A Comparative Computerized Tomographic Scan and Roentgenographic Study. J Indian Acad Oral Med Radiol. 2010; 22(2): 81-7.

25) N'Guyen T, Gorse FC, Vacher C. Anatomical modifications of the mid palatal suture during ageing: a radiographic study. Surg Radiol Anat. 2007; 29(3): 253-9. doi: 10.1007/s00276-007-0204-6. PMID: 17377734.

26) Cohen MM Jr. Sutural biology and the correlates of craniosynostosis. Am J Med Genet. 1993; 47(5): 581 616. doi: 10.1002/ajmg.1320470507. PMID: 8266985.

27) Katsaros C, Zissis A, Bresin A, Kiliaridis S. Functional influence on sutural bone apposition in the growing rat. Am J Orthod Dentofacial Orthop. 2006; 129(3): 352-7. doi: 10.1016/j.ajodo.2004.09.031. PMID: 16527630 .

28) de Melo Mde F, Melo SL, Zanet TG, Fenyo-Pereira M. Digital radiographic evaluation of the midpalatal suture in patients submitted to rapid maxillary expansion. Indian J Dent Res. 2013; 24(1): 76-80. doi: 10.4103/0970-9290.114960. PMID: 23852237.

29) Revelo B, Fishman LS. Maturational evaluation of ossification of the midpalatal suture. Am J Orthod Dentofacial Orthop. 1994; 105(3): 288-92. doi: 10.1016/S0889-5406(94)70123-7. PMID: 8135215. 